\title{
Diagnosing scrub typhus: meticulous physical examination is the key
}

\author{
Chandrasekharan Rajasekharan, ${ }^{1}$ Joy Anu, ${ }^{1}$ Vinayakumar Neeraj, ${ }_{1}^{1}$ \\ Rajasekharan Parvathy ${ }^{2}$
}

${ }^{1}$ Department of Internal Medicine, Medical College Hospital, Thiruvananthapuram, Kerala, India

${ }^{2}$ Department of Internal Medicine, MOSC, Medical College, Ernakulam, Kerala, India

\section{Correspondence to}

Professor Chandrasekharan Rajasekharan,

drcrajasekharan@yahoo.com

Accepted 26 October 2014
CrossMark

To cite: Rajasekharan $C$ Anu J, Neeraj $\mathrm{V}$, et al. BMJ Case Rep Published online: [please include Day Month Year] doi:10.1136/bcr-2014204695

\section{DESCRIPTION}

A 50-year-old woman and a 45-year-old man were referred to the internal medicine department with a history of high-grade intermittent fever, headache, myalgia and non-productive cough of 10 days duration. Except for fever, the general examination and physical examination were unremarkable. No rashes or other skin lesions were seen on the exposed parts on routine general examination. The laboratory investigations, including complete blood count and erythrocyte sedimentation rate, were normal; both patients had elevated $\mathrm{C}$ reactive protein levels and modest elevation of aspartate aminotransferase and alanine aminotransferase levels. Blood cultures showed no growth. Both patients responded to paracetamol tablets orally with temporary defervescence. A review physical examination of the first patient on the sixth day showed a round to oval plaque with erythematous halo and central haemorrhagic crust on the undersurface of the left breast with no regional adenopathy, suggestive of an eschar (figure 1A) and examination of the second patient revealed an oval plaque with haemorrhagic crust and peripheral collaret with scales suggestive of a healing eschar (figure 1B). IgM scrub was positive in both patients and was confirmed by PCR using the scab specimen at the bite site. Both cases were treated with doxycline $100 \mathrm{mg}$ twice daily and over the days both patients improved with prompt defervescence.

Scrub typhus is an acute febrile illness with the characteristics of high fever, headache and rash. The disease is caused by Orientia (formerly Rickettsia) tsutsugamushi. It is a major febrile disease that occurs in south Asian countries during scrub typhus season. ${ }^{1}$ Eschar is an important sign for the diagnosis of scrub typhus. It is very difficult to make out rashes in patients on the Indian subcontinent owing to skin colour.

\section{Learning points}

Lacking the classical textbook presentations, scrub typhus is often missed or diagnosed late. Eschar with or without regional painful adenopathy is a reliable indicator of scrub typhus and is seen in more than $90 \%$ of patients, and is typically formed at the time of the manifestation of the other symptoms. ${ }^{1}$

- Early diagnosis is crucial as delayed administration of effective antibiotics can cause fatal complications, including pneumonitis and meningitis, which are causes of death in several patients with scrub typhus. ${ }^{2}$

- The primary regions of eschar formation in men are within $30 \mathrm{~cm}$ below the umbilicus, the lower limbs and the front chest above the umbilicus. The most prevalent development site in women is the front chest above the umbilicus, which is different from men, in whom the majority of eschars were detected on the front anterior chest. ${ }^{1}$ Methodic and meticulous physical examination of the whole body, including those areas covered by clothing and genitalia, is recommended for the sake of identifying an eschar in patients coming from an endemic area to avoid unnecessary and cumbersome investigations in patients presenting with prolonged fever.

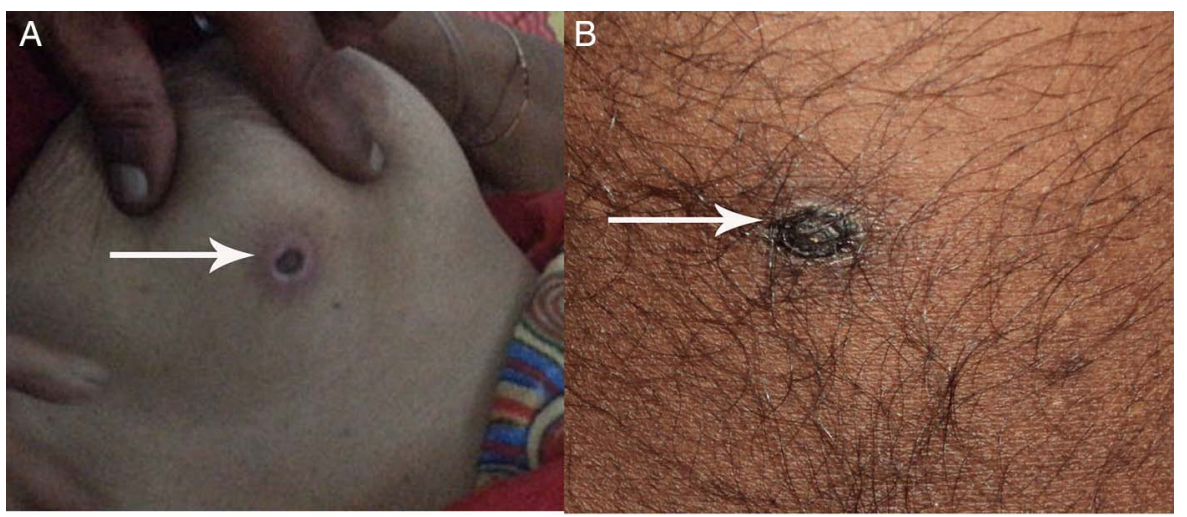

Figure 1 (A) Round to oval plaque with erythematous halo and central haemorrhagic crust in the undersurface of the left breast in the first patient, suggestive of an eschar. (B) Oval plaque with haemorrhagic crust and peripheral collaret inferior to the umbilicus with scales suggestive of a healing eschar in the second patient. 


\section{Images in...}

The main differentials of eschar are tularaemia and anthrax. In the former, the eschar is commonly seen in extremities with enlarged and inflamed tender regional lymph nodes that may also break down, whereas in anthrax a central eschar is surrounded by a ring of oedema and erythema surmounted by small vesicles, which are typically painless and seen in the exposed areas of the upper extremities and to a lesser extent on the head and neck.

Contributors CR was the primary physician under whom the patient was admitted and treated. He was responsible for conception of the idea of the manuscript and revision of the manuscript. JA was responsible for revising the manuscript. VN and RP wrote the initial draft, took and formatted the images and collected references.

Competing interests None.

Provenance and peer review Not commissioned; externally peer reviewed.

\section{REFERENCES}

1 Kim DM, Won KJ, Park CY, et al. Distribution of eschars on the body of scrub typhus patients: a prospective study. Am J Trop Med Hyg 2007;76:806-9.

2 Silpapojakul K, Chupuppakarn S, Yuthasompob S, et al. Scrub and murine typhus in children with obscure fever in the tropics. Pediatr Infect Dis J 1991;10:200-3.

Copyright 2014 BMJ Publishing Group. All rights reserved. For permission to reuse any of this content visit http://group.bmj.com/group/rights-licensing/permissions.

BMJ Case Report Fellows may re-use this article for personal use and teaching without any further permission.

Become a Fellow of BMJ Case Reports today and you can:

- Submit as many cases as you like

- Enjoy fast sympathetic peer review and rapid publication of accepted articles

- Access all the published articles

- Re-use any of the published material for personal use and teaching without further permission

For information on Institutional Fellowships contact consortiasales@bmjgroup.com

Visit casereports.bmj.com for more articles like this and to become a Fellow 